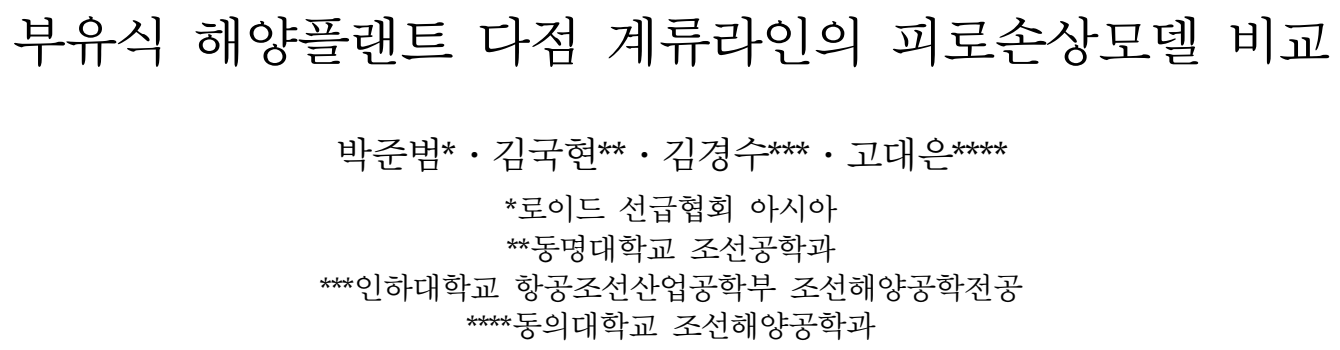

\title{
Comparison of Fatigue Damage Models of Spread Mooring Line for Floating Type Offshore Plant
}

\author{
Jun-Bum Park*, Kookhyun Kim**, Kyung-Su Kim** and Dae-Eun Ko ${ }^{* * * *}$ \\ *Lloyd's Register Asia, Busan, Korea \\ **Department of Naval Architecture, Tongmyong University, Busan, Korea \\ ***Division of Aerospace, Naval Architecture and Industrial Engineering, Inha University, Inchon, Korea \\ ****Department of Naval Architecture and Ocean Engineering, Dong-Eui University, Busan Korea
}

KEY WORDS: Floating type offshore plant 부유식 해양플랜트, Spread mooring line 다점계류라인, Fatigue damage assessment 피로손 상평가, Wide band loading광대역 하중, Fatigue damage model피로손상모델

\begin{abstract}
The mooring lines of a floating type offshore plant are known to show wide banded and bimodal responses. These phenomena come from a combination of low and high frequency random load components, which are derived from the drift restoring motion characteristic and windsea, respectively. In this study, fatigue models were applied to predict the fatigue damage of mooring lines under those loads, and the result were compared. For this purpose, seven different fatigue damage prediction models were reviewed, including mathematical formula. A FPSO (floating, production, storage, and offloading) with a $4 \times 4$ spread catenary mooring system was selected as a numerical model, which was already installed at an offshore area of West Africa. Four load cases with different combinations of wave and wind spectra were considered, and the fatigue damage to each mooring line was estimated. The rain flow fatigue damage for the time process of the mooring tension response was compared with the results estimated by all the fatigue damage prediction models. The results showed that both Benasciutti-Tovo and JB models could most accurately predict wide banded bimodal fatigue damage to a mooring system.
\end{abstract}

\section{1. 서 론}

최근 들어 육상과 천해에서의 유전고갈과 고유가 기조 유지로 심해 유전개발에 대한 관심이 증대되고 있으며, 그에 따른 부유식 해양플랜트의 발주가 이어지고 있다. 부유식 해양플랜트는 풍압, 파랑, 너울 등에 의한 외부하중을 받게 되며, 이와 더불어 부유 식 해양플랜트의 위치를 유지하기 위해 설치된 계류라인으로부터 기인한 하중으로 광대역 동적응답이 나타나게 된다. 이러한 광 대역 동적응답은 파랑하중으로 인한 해양플랜트의 고주파 운동 응답과 현수선 계류 방식으로 인한 해양플랜트의 표류-복원(Driftrestoring) 저주파수 운동응답으로 구성된다고 알려져 있으며, 계 류라인의 피로수명을 신뢰성있게 평가하기 위해서는 이를 고려
한 피로수명 평가기법 적용과 이에 대한 타당성 검증이 요구된다. 일반적으로 부유식 해양플랜트 광대역 동적응답을 고려할 수 있는 피로평가기법으로는 시간영역피로평가법과 통계피로해석법 이 대표적이다. 시간영역피로평가법은 시간영역 동적응답으로부 터 레인플로우 집계방법(Rainflow cycle counting method)을 사 용하여 응력범위와 그 빈도를 구하고 여기에 재료특성인 S-N선도 (또는 T-N선도)와 Palmgren-Miner 선형누적법을 적용하여 피 로수명을 예측하는 방법이다(API, 2005). 이를 이용해 정도 높고 직관적인 결과를 도출할 수 있으나 계산비용이 높아 실제 설계로 의 적용이 어려운 실정이다. 반면, 통계피로해석법(DNV, 2008; ABS, 2006; Lloyd, 2002; KR, 2010)은 응답스펙트럼으로부터 피 로손상모델을 사용하여 피로손상을 예측하는 방법을 말하며, 시

Received 14 May 2013, revised 17 September 2013, accepted 24 September 2013

Corresponding author Kookhyun Kim: +82-51-629-1658, kimk@tu.ac.kr

(c) 2013, The Korean Society of Ocean Engineers 
간영역피로평가법에 비해 계산비용이 상대적으로 적은 장점이 있다.

한편, 통계피로해석법을 이용한 신뢰성있는 피로수명평가를 위 해서는 적절한 피로손상모델이 적용되어야 한다. 피로손상모델이 란 시간영역피로평가법을 이용해 구한 피로손상값에 상응한 결 과를 얻을 수 있도록 응답스펙트럼의 모멘트와 T-N(Tensioncycle) 또는 S-N(Stress-cycle)선도를 정의하는 재료특성치를 인 자로 하여 구성한 식을 말한다. 피로손상모델은 광대역 하중으로 인한 피로손상값에 상응하는 보정계수를 제공하는 모델과 레인 플로우 응력범위분포(Rainflow stress range distribution)를 근사 하는 모델로 구분된다. 보정계수를 제공하는 피로손상모델로는 광 대역 응답스펙트럼을 기반으로 한 Wirsching-Light모델(Wirsching and Light, 1980), Benasciutti-Tovo모델(Benasciutti and Tovo, 2005) 등과, 응답스펙트럼을 서로 다른 두 개의 협대역 주파수를 가지는 바이모달 (Bimodal)로 가정하는 Jiao-Moan모 델(Jiao and Moan, 1990), Sakai-Okamura모델(Sakai and Okamura, 1995) 등이 있다. 반면, 레인플로우 응력범위분포를 근사 하는 피로손상모델로는 Dirlik모델(Dirlik, 1985), Zhao-Baker 모 델(Zhao and Baker, 1992), JB모델(Park, 2011) 등이 있다.

본 연구에서는 각각의 피로손상모델을 소개하고, 사례연구를 통해 부유식 해양플랜트 다점계류라인 피로손상평가에 대한 적합 한 피로손상모델을 제안한다. 이를 위해 너울 및 파랑하중이 크지 않은 서아프리카 해역에 설치되는 FPSO(Floating, production, storage and offloading)의 다점계류시스템으로 많이 사용되고 있는 수동형 계류라인에 대한 응답스펙트럼해석을 수행하고 그 결과 를 각각의 피로손상모델에 적용한다. 이로부터 광대역 동적하 중을 받는 해양플랜트 계류라인의 피로수명평가에 적합한 모델 을 제안하고자 한다.

\section{2. 피로손상모델}

\subsection{Wirsching-Light 모델}

Wirsching-Light 모델은 협대역 피로손상값에 보정계수를 고 려하여 광대역 피로손상값을 추정하는 모델이다. 이 모델은 광 대역성이 비교적 약한 하중의 형태를 갖는 고정식 해양구조물의 피로해석을 대상으로 개발되었으며, 최소자승법을 사용하여 협대 역 피로손상과 광대역 피로손상의 관계를 유도하였다(Wirsching and Light, 1980).

광대역 피로손상값 $D_{W L}$ 은 식 (1)과 같이 계산된다

$$
D_{W L}=\rho_{W L} D_{N B}
$$

여기서, $\rho_{W L}$ 과 $D_{N B}$ 는 식 (2)와 식 (3)으로 정의되는 보정계수와 협대역 피로손상값을 각각 나타낸다.

$$
\begin{aligned}
& \rho_{W L}=a(m)+[1-a(m)](1-\epsilon)^{b(m)} \\
& D_{N B}=\frac{v_{0}}{c}\left(2 \sqrt{2 m_{0}}\right)^{m} \Gamma(1+m / 2)
\end{aligned}
$$

여기서, $\Gamma(\cdot)$ 는 감마 함수이며, $\epsilon=\sqrt{1-\alpha_{2}^{2}}, a(m)$ 과 $b(m)$ 은 협대역과 광대역 피로손상값에 대한 관계를 최소자승법으로 유
도하여 식 (4)와 식 (5)와 같이 적용한다.

$$
\begin{aligned}
& a(m)=0.926-0.033 m \\
& b(m)=-2.323+1.587 m
\end{aligned}
$$

이때, $m$ 은 계류라인의 피로수명을 평가하기 위한 T-N 선도 의 기울기이고 $c$ 는 이 선도의 피로 재료 상수로써, 일반적으로 $\mathrm{API}($ American petroleum institute)에서 제시한 값을 사용한다. $\alpha_{n}$ 은 응답스펙트럼 $S(\omega)$ 의 밴드폭으로써 식 (6)으로 정의되고, $v_{o}$ 와 $m_{n}$ 은 응답스펙트럼의 영점교차주기와 $n$ 차 스펙트럼 모 멘트로써, 식 (7)과 식 (8)로 각각 산정한다.

$$
\begin{aligned}
& \alpha_{n}=\frac{m_{n}}{\sqrt{m_{0} m_{2 n}}} \\
& v_{0}=\frac{1}{2 \pi} \sqrt{\frac{m_{2}}{m_{0}}} \\
& m_{n}=\int_{0}^{\infty} \omega^{n} S(\omega) d \omega
\end{aligned}
$$

본 모델은 기본가정이 한 개의 기울기 $m$ 을 갖는 $\mathrm{T}-\mathrm{N}$ 곡선의 가정하여 개발되었기 때문에, 두 개의 기울기에 대한 T-N곡선 적용시 피로손상의 오차를 포함할 수밖에 없다. 이는 수정계수 를 사용하는 모든 모델이 공통적으로 갖는 문제점이기도 하다. 또한 이 모델은 단순하고 약한 광대역 응답에 합리적인 값을 제공하므로 상선의 피로해석에 주로 적용되고 있다.

\subsection{Benasciutti-Tovo 모델}

Benasciutti-Tovo모델은 식 (9)와 같이 레인플로우 집계방법으 로 얻은 피로손상값 $D_{R F C}$ 이 협대역 피로손상값 $D_{N B}$ 와 응력범 위 계산 방법(Range counting method)으로 얻은 피로손상값 $D_{R C}$ 사이에 존재한다는 사실로부터 식 (10)과 같이 유도된 다.(Benasciutti and Tovo, 2005).

$$
\begin{aligned}
& D_{R C} \leq D_{R F C} \leq D_{N B} \\
& D_{B T}=b_{B T} D_{N B}+\left(1-b_{B T}\right) D_{R C}
\end{aligned}
$$

여기서 $b_{B T}$ 은 가중치를 나타낸다.

식(10)에서 $D_{R C}$ 는 Madsen(Madsen et al., 1986)이 제안한 식 (11)의 근사식을 대입하여 정리하면 최종적인 피로손상값 $D_{B T}$ 는 식 (12)와 같이 유도된다.

$$
\begin{aligned}
& D_{R C} \cong D_{N B} \alpha_{2}^{m-1} \\
& D_{B T}=\left[b_{B T}+\left(1-b_{B T}\right) \alpha_{2}^{m-1}\right] D_{N B}=\rho_{B T} D_{N B}
\end{aligned}
$$

여기서, 가중치 $b_{B T}$ 는 식 (13)로 제안하였다.

$$
b_{B T} \cong \frac{\left(\alpha_{1}-\alpha_{2}\right)\left[1.112\left\{1+\alpha_{1} \alpha_{2}-\left(\alpha_{1}+\alpha_{2}\right)\right\} e^{2.11 \alpha_{2}}+\left(\alpha_{1}-\alpha_{2}\right)\right]}{\left(\alpha_{2}-1\right)^{2}}
$$

\subsection{Jiao-Moan 모델}

Jiao-Moan 모델은 응답 스펙트럼의 형태가 쌍봉형인 바이모 달 스펙트럼을 가정하여 피로손상값을 추정하는 모델이다(Jiao and Moan, 1990). 바이모달 과정 $X(t)$ 는 저주파 협대역 과정 
$X_{1}(t)$ 와 고주파 협대역 과정 $X_{2}(t)$ 의 합이라 가정한다. 그들은 $X(t)$ 의 특성을 유지하면서 계산의 편의를 위해, 무차원화 된 $X^{*}(t)$ 를 사용하고 이에 대한 분산을 식 (14)으로 표현하였다.

$$
m_{0, X}=m_{0,1}^{*}+m_{0,2}^{*}=1
$$

여기서, $m_{0,1}^{*}=m_{0,1} /\left(m_{0,1}+m_{0,2}\right), \quad m_{0,2}^{*}=m_{0,2} /\left(m_{0,1}+m_{0,2}\right)$ 이며, $m_{0,1}$ 과 $m_{0,2}$ 는 각각 $X_{1}(t)$ 와 $X_{2}(t)$ 의 0 차 스펙트럼 모멘트이다. 한편, 스펙트럼 모멘트는 식 (15)와 같이 근사하였다.

$$
m_{n, X} \cong v_{0,1}^{n} m_{0,1}^{*}+v_{0,2}^{n} m_{0,2}^{*}
$$

여기서, $v_{0,1}$ 과 $v_{0,2}$ 는 각각 저주파 협대역 과정 $X_{1}(t)$ 와 고주파 협대역 과정 $X_{2}(t)$ 의 영점 교차 주기이다.

이 때, 바이모달 과정 $X(t)$ 의 영점 교차 주기 $v_{0, X}$ 는 식 (15) 을 사용하여 식 (16)과 같이 유도된다.

$$
v_{0, X}=\sqrt{\frac{m_{2, X}}{m_{0, X}}} \cong \sqrt{v_{0,1}^{2} m_{0,1}^{*}+v_{0,2}^{2} m_{0,2}^{*}}
$$

본 모델의 바이모달 과정 $X(t)$ 의 피로손상값은 식 (17)과 같 으며, 이때의 보정계수 $\rho_{J M}$ 은 식 (18)와 같이 제안하였다.

$$
\begin{aligned}
D_{J M} & =\rho_{J M} D_{N B} \\
\rho_{J M} & =\frac{v_{0, P}}{v_{0, X}}\left[m_{0,1}^{* \frac{m}{2}+2}\left(1-\sqrt{\frac{m_{0,2}^{*}}{m_{0,1}^{*}}}\right)+\sqrt{\pi m_{0,1}^{*} m_{0,2}^{*}} \frac{m I\left(\frac{m+1}{2}\right)}{I\left(\frac{m}{2}+1\right)}\right] \\
& +\frac{v_{0,2}}{v_{0, X}} m^{*}{ }_{0,2}^{\frac{m}{2}}
\end{aligned}
$$

여기서, $v_{0, P}=m_{0,1}^{*} v_{0,1} \sqrt{1+\frac{m_{0,2}^{*}}{m_{0,1}^{*}}\left(\frac{v_{0,2}}{v_{0,1}} \delta_{2}\right)^{2}}$ 이며, $\delta_{2}$ 는 $X_{2}^{*}(t)$ 의 Vanmarcke 밴드폭 매개변수로써, API코드에서는 0.1의 값을 제안하고 있다.

본 모델은 저주파 응답과 고주파 응답 모두가 피로손상에 주 된 원인이 될 때 정확한 값을 준다. 하지만 피로손상이 주로 저 주파로 인해 영향을 받을 경우, 과도한 피로손상값이 추정되는 단점이 있다. 또한, 저주파와 고주파 성분이 모두 협대역이라는 것을 가정하여 본 모델을 유도되었기 때문에, 저주파 응답과 고 주파 응답 자체가 광대역 특성을 보이는 경우는 부정확한 값을 제공할 수 있다.

\subsection{Sakai-Okamura 모델}

Sakai-Okamura 모델은 Jiao-Moan 모델과 마찬가지로 응답스 펙트럼을 바이모달 스텍트럼으로 가정하여 피로손상값을 추정 하는 모델이다(Sakai and Okamura, 1995). 본 모델에서 저주파 수 $\overline{N_{L}}$ 과 고주파수 $\overline{N_{S}}$ 는 식 (19), 식 (20)에 보인 바와 같이 이 각각 $X_{1}(t)$ 및 $X_{2}(t)$ 의 평균 주기와 관찰시간의 곱이라고 가정 하며, 이는 저주파 성분과 고주파 성분의 상호간섭이 무시할 만 한 수준임을 의미한다.

$$
\begin{aligned}
& \overline{N_{L}} \cong \overline{N_{0,1}}=\frac{\omega_{1}}{2 \pi} T \\
& \overline{N_{L}} \cong \overline{N_{0,2}}=\frac{\omega_{2}}{2 \pi} T
\end{aligned}
$$

이로부터 본 모델을 적용한 피로손상 값은 식 (21)과 같이 저
주파수 성분과 고주파수 성분의 합으로 유도된다.

$$
\begin{aligned}
D_{S O} & =\frac{1}{2 \pi c}\left[\omega_{1} \int_{0}^{\infty} S^{m} p_{S_{1}}(s) d S+\omega_{2} \int_{0}^{\infty} S^{m} p_{S_{2}}(s) d S\right] \\
& =\frac{1}{2 \pi c} I\left(1+\frac{m}{2}\right)\left[\omega_{1}\left(\sqrt{2 m_{0,1}}\right)^{m}+\omega_{2}\left(\sqrt{2 m_{0,2}}\right)^{m}\right]
\end{aligned}
$$

여기서, $\omega_{1}\left(=\sqrt{m_{2,1} / m_{0,1}}\right)$ 과 $\omega_{2}\left(=\sqrt{m_{2,2} / m_{0,2}}\right)$ 는 평균주파수이다.

이를 토대로 식 (22)와 같은 피로손상 모델을 제안하였다.

$$
D_{S O}=\frac{2^{m / 2}}{2 \pi c} \Gamma\left(1+\frac{m}{2}\right)\left[m_{0,1}^{(m-1) / 2} m_{2,1}^{1 / 2}+m_{0,2}^{(m-1) / 2} m_{2,2}^{1 / 2}\right]
$$

본 모델은 $X_{1}(t)$ 와 $X_{2}(t)$ 의 상호간섭 효과를 무시하였기 때 문에, 과소평가된 피로손상값을 제공하는 경향이 있다.

\subsection{Zhao-Baker 모델}

Zhao-Baker모델은 레인플로우 응력범위분포가 한개의 와이 블확률분포(Weibull probability density funciton)와 한개의 레 일리확률분포(Rayleigh probability density funciton)의 조합으 로 이루어져 있다고 식 (23)과 같이 가정하는 모델이며,, 이로부 터 유도된 피로손상값은 식 (24)와 같다(Zhao and Baker, 1992).

$$
\begin{aligned}
& p_{Z B}=w a b z^{b-1} e^{-a z}+(1-w) z e^{-z^{2} / 2} \\
& D_{Z B}=\frac{v_{p}}{c}\left(2 \sqrt{m_{0}}\right)^{m}\left[w a^{m / b} \Gamma\left(1+\frac{m}{b}\right)+(1-w) 2^{m / 2} \Gamma\left(1+\frac{m}{2}\right)\right]
\end{aligned}
$$

여기서, $v_{p}=\frac{1}{2 \pi} \sqrt{\frac{m_{4}}{m_{2}}}$ 는 피크 교차 주기이고 가중치 $w$ 는 식 (25)와 같다.

$$
w=\frac{1-\alpha_{2}}{1-\sqrt{\frac{2}{\pi}} \Gamma\left(1+\frac{1}{b}\right) \alpha^{-1 / b}}
$$

여기서,

$$
\begin{aligned}
& \alpha=8-7 \alpha_{2} \\
& b= \begin{cases}1.1, & \text { if } \alpha_{2}<0.9 \\
1.1+9\left(\alpha_{2}-0.9\right), & \text { if } \alpha_{2} \geq 0.9\end{cases}
\end{aligned}
$$

\subsection{Dirlik 모델}

Dirlik모델은 식 (26)과 같이 레인플로우 응력범위분포가 한개 의 지수확률분포(Exponential probability density funciton)와 두개의 레일리확률분포의 조합으로 이루어져 있다고 가정하고 유도한 피로손상모델이며(Dirlik, 1985). 본 모델에 의한 피로손 상값은 식 (27)와 같이 산정한다.

$$
\begin{aligned}
& p_{\text {Dirlik }}(z)=\frac{D_{1}}{Q} e^{-\frac{z}{Q}}+\frac{D_{2} z}{R^{2}} e^{-\frac{z^{2}}{2 R^{2}}}+D_{1} z e^{-\frac{z^{2}}{2}} \\
& D_{\text {Dirlik }}=\frac{v_{p}}{c}\left(2 \sqrt{m_{0}}\right)^{m} \\
& {\left[D_{1} Q^{m} \Gamma(1+m)+(\sqrt{2})^{m} I\left(1+\frac{m}{2}\right)\left(D_{2} \mid R^{m}+D_{3}\right)\right]}
\end{aligned}
$$

여기서, $z\left(=\Delta \sigma /\left(2 \sqrt{m_{0}}\right)\right.$ 는 표준화된 독립변수이며,

$$
\begin{aligned}
& D_{3}=1-D_{1}-D_{2}, \quad D_{2}=\frac{1-\alpha_{2}-D_{1}+D_{1}^{2}}{1-R}, D_{1}=\frac{2\left(x_{m}-\alpha_{2}^{2}\right)}{1-\alpha_{2}^{2}}, \\
& Q=\frac{1.25\left(\alpha_{2}-D_{3}+D_{2} R\right)}{D_{1}}, R=\frac{\alpha_{2}-x_{m}+D_{1}^{2}}{1-\alpha_{2}-D_{1}+D_{1}^{2}}, x_{m}=\frac{m_{1}}{m_{0}}\left(\frac{m_{2}}{m_{4}}\right)^{\frac{1}{2}}
\end{aligned}
$$


이다.

본 모델은 협대역과 광대역 스펙트럼에 대해 안정적인 피로 손상값을 주는 것으로 알려져 있다.

\section{$2.7 \mathrm{JB}$ 모델}

$\mathrm{JB}$ 모델은 레인플로우 응력범위분포를 한개의 반쪽 가우시안 확률분포(Half gaussian $\mathrm{PDF})$ 와 두개의 레일리확률분포 (Rayleigh PDF)를 사용하여 식 (28)과 같이 근사한 모델이며, 이로부터 유도된 피로손상모델은 식 (29)와 같다(Park, 2011).

$$
\begin{gathered}
p_{J B}=c_{1} \frac{2}{\sqrt{2 \pi} \sigma_{\text {Gau }}} e^{-\frac{z^{2}}{2 \sigma_{\text {Gau }}^{2}}}+c_{2} \frac{z}{\sigma_{\text {Ray }}^{2}} e^{-\frac{z^{2}}{2 \sigma_{\text {Ray }}^{2}}}+c_{3} z e^{-\frac{z^{2}}{2}} \\
D_{J B}=\frac{T_{d} v_{p}}{c}\left(28 \sqrt{2 m_{0}}\right)^{m} \\
{\left[\frac{c_{1}}{\sqrt{\pi}} \sigma_{\text {Gau }}^{m} I\left(\frac{m+1}{2}\right)+c_{2} \sigma_{\text {Ray }}^{m} I\left(1+\frac{m}{2}\right)+c_{3} I\left(1+\frac{m}{2}\right)\right]}
\end{gathered}
$$

이 때, 위 식에 사용된 계수들은 식 (30)에서 식 (39)으로 정의 되는데, 계수 $c_{2}, c_{3}$ 그리고 $\sigma_{G a u}$ 이 음수가 되는 경우를 배제하 기 위해 크게 두 가지의 조건으로 구분하여 적용한다.

우선 $c_{2}>0\left(C_{M R R(2)}>C_{M R R(3)}\right), \quad c_{3}>0\left(\alpha_{2}<C_{M R R(3)} / C_{M R R(2)}\right)$, $\sigma_{G a u}>0\left(\alpha_{2}>\left[C_{M R R(2)}+\sqrt{C_{M R R(2)}^{2}+4\left(C_{M R R(2)}-C_{M R R(3)}\right)}\right] / 2\right.$ 또 는 $\left.\alpha_{2}<\left[C_{M R R(2)}-\sqrt{C_{M R R(2)}^{2}+4\left(C_{M R R(2)}-C_{M R R(3)}\right)}\right] / 2\right)$ 인 경우, 식 (30)에서 식 (34)의 계수들을 적용하며,

$$
\begin{aligned}
& c_{1}=1-c_{2}-c_{3} \\
& c_{2}=\frac{C_{M R R(2)}-C_{M R R(3)}}{\sigma_{R a y}^{2}\left(1-\sigma_{\text {Ray }}\right)} \\
& c_{3}=\frac{-\sigma_{R a y} C_{M R R(2)}+C_{M R R(3)}}{1-\sigma_{R a y}} \\
& \sigma_{\text {Gau }}=\frac{C_{M R R(1)}-c_{2} \sigma_{\text {Ray }}-c_{3}}{V_{1} c_{1}} \\
& \sigma_{\text {Ray }}=\alpha_{2}
\end{aligned}
$$

그 외의 경우에는 식 (35)에서 식 (40)의 계수들을 적용한다.

$c_{1}=1-c_{3}$

$c_{2}=0$

$c_{3}=C_{M R R(3)}$

$\sigma_{\text {Gau }}=\frac{C_{M R R(1)}-c_{3}}{V_{1} c_{1}}$

$\sigma_{\text {Ray }}=\alpha_{2}$

여기서, $\quad V_{1}=\frac{\Gamma(1)}{\sqrt{\pi} \Gamma(1.5)}, \quad C_{M R R(1)}=\alpha_{2}, \quad C_{M R R(2)}=\sigma_{0.95} \sigma_{1.97}$, $C_{M R R(3)}=\sigma_{0.54} \sigma_{0.93} \sigma_{1.95}$ 이다.

본 모델은 협대역 및 광대역 스펙트럼에 대해 안정적인 피로 손상값을 주는 것으로 평가된다.

\section{3. 수치해석 및 고찰}

\section{1 해석모델 및 해석조건}

수치해석은 너울 및 파랑하중이 크지 않은 서아프리카 해역에 설치되는 FPSO(Floating, Produduction, Storage and Offloading)의 다점계류시스템으로 많이 적용되고 있는 수동형 계류 라인을 대상으로 수행하였으며, 이에 대한 주요 제원은 Table 1 에 요약한 바와 같다.

한편, 연결된 계류라인의 응답스펙트럼은 계류해석 프로그램 인 ARIANE7(BV, 2008)을 사용하여 계산하였다. 해석모델은 Fig. 1과 Fig. 2에서 보인 체인과 와이어가 복합적으로 구성된 $4 \times 4$ 방사형 다점 계류 시스템이며, 대상 해역의 깊이는 $785 \mathrm{~m}$ 이다.

Table 1 Main partidculars of objective FPSO (Lim et al., 2010)

\begin{tabular}{cc}
\hline \hline L.O.A (m) & 325.0 \\
Breadth (m) & 61.0 \\
Depth (m) & 32.0 \\
Draft (m) & 24.5 \\
LCG (m) & 170.7 \\
VCG (m) & 19.1 \\
G.M (m) & 5.8 \\
\hline
\end{tabular}

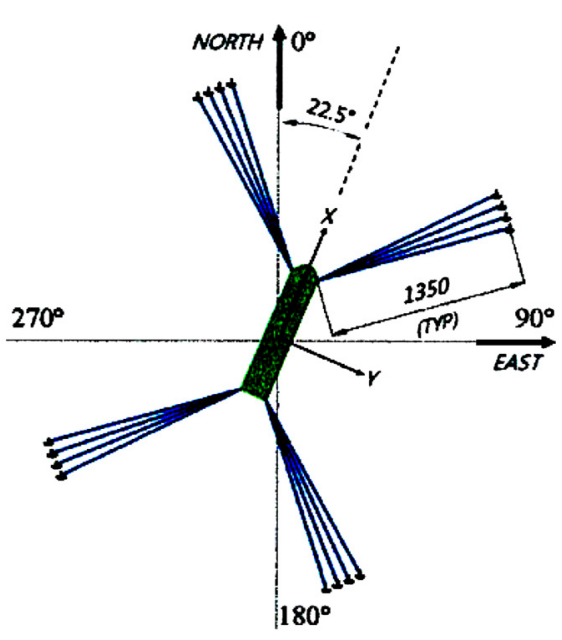

Fig. 1 Arrangement of passive spread mooring system for FPSO (Lim et al., 2010)

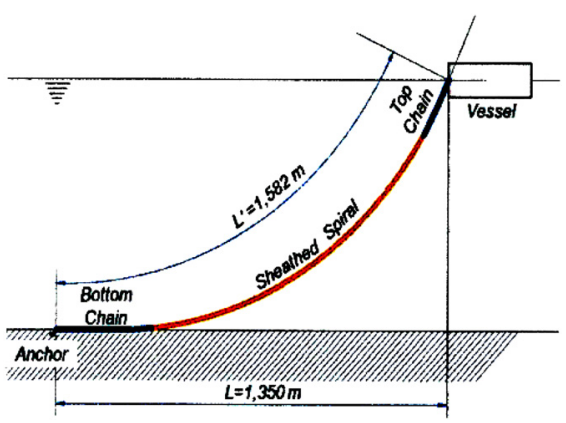

Fig. 2 Configuration of mooring line (Lim et al., 2010) 
한편, 계류라인의 피로수명을 평가할때는 응력범위보다 인장 범위를 사용하는 것이 일반적이며, API에서도 계류라인 피로수 명 평가하는데 S-N선도가 아닌 T-N선도를 제시하고 있다. 따라 서 본 연구에서는 T-N 선도를 사용해 계류라인 인장력 응답스 펙트럼으로부터 피로손상값을 계산하였다. 또한, 피로손상 모델 식에서 알 수 있듯이 피로손상값을 상대비교할 때에는 피로 재 료 상수 $c$ 가 서로 상쇄되므로 T-N선도의 기울기 값만을 비교하 였다. 참고로, 본 연구에서 적용한 $\mathrm{T}-\mathrm{N}$ 선도 기울기 $m$ 은 3 과 5 이다.

다양한 계류라인의 응답을 얻기 위한 실제 해역 환경데이터 와 유사한 정도의 단일 및 복합 환경하중들은 Table 2 같이 선 정하였다. 이때, 사용된 환경하중들은 본 연구에서 적용하는 피 로손상모델들에 대해 신뢰성있는 비교연구가 이루어질 수 있도 록 가능한 한 다양한 환경조건을 고려하였다.

\section{2 해석결과 및 비교 분석}

앞서 소개한 피로손상 모델들의 타당성은 Park et al.(2011)이 제안한 시간영역피로평가방법을 사용하여 얻은 값과의 상대비 교를 통하여 검토하였다. 이를 위해 계류라인 응답스펙트럼을 역푸리어 변환하여 시간영역으로 0.1 초 간격으로 600 시간을 확 장하고 그 결과로부터 레인플로우 집계방법을 사용하여 응력범 위와 그 빈도를 구하여 피로손상값을 얻어 이를 기준으로 피로 손상모델들의 정확도를 비교분석하였다.

\subsection{1 응답 스펙트럼}

16 개의 계류라인에 4 개의 환경조건을 적용함으로써 총 64 개 의 응답스펙트럼을 도출하였으며, 이에 2장에 소개된 피로손상 모델들을 적용하여 피로손상값을 계산하였다. Fig. 3은 환경하 중조건 1과 2을 계류라인 2와 1에 각각 적용할 경우에 대한 응 답스펙트럼을 예시로 나타낸 것이다. 이때, 계류라인 강성으로 인해 발생되는 저주파수 영역 하중이 플랫폼거동으로 인해 발 생하는 고주파수 영역에서의 하중보다 상대적으로 매우 크게 나타나므로 수직축을 로그 눈금간격으로 표시하였다.

응답스펙트럼으로 알 수 있듯이 계류라인의 동적 응답은 전 형적인 광대역 바이모달 스펙트럼을 이루고 있다. 한편, 바이모 달 스펙트럼을 기반으로 한 피로손상모델을 적용하기 위해서는
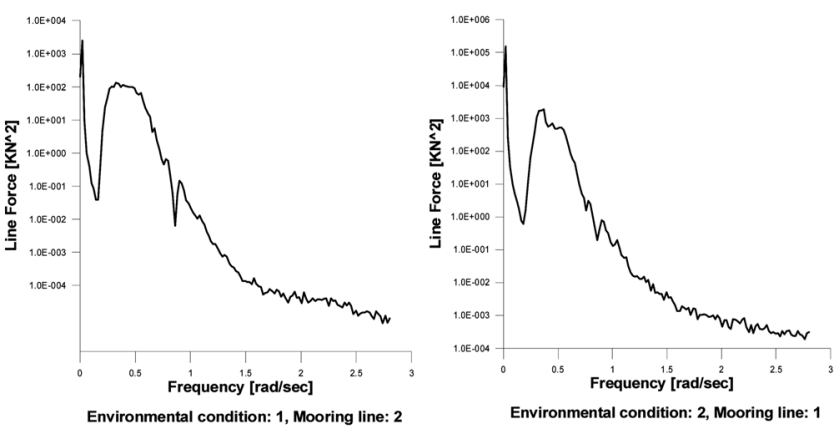

Fig. 3 Representative response spectra of mooring lines

응답스펙트럼을 저주파수 영역과 고주파수 영역으로 구분하여 야 한다. 본 연구에서는 그 기준 주파수를 저주파 영역의 저점 인 $0.16 \mathrm{rad} / \mathrm{sec}$ 로 선정하였다.

\subsection{2 피로손상모델 비교 분석}

앞서 계산된 64 개의 응답스펙트럼에 각각의 피로손상모델들 을 적용하여 산정한 피로손상값은 Fig. 4 에 $m=3$ 인 경우와 $m=5$ 인 경우로 구분하여 도시하였다. 이 때, 비교결과는 각각 의 피로손상모델을 적용한 피로손상값 $D(M o d e l s)$ 와 시간영역피 로평가법을 사용하여 얻은 피로손상값 $D(R F D)$ 의 비 $D(=D$ (Models)/ $D(R F D))$ 산출하고 Vanmarke 밴드폭 매개변수 $\left(\delta=\sqrt{1-\frac{m_{1}^{2}}{m_{0} m_{2}}}\right)$ 에 대해 정리하였다. 여기서, Vanmarke 밴드폭 매개변수는 응 답스펙트럼의 협대역과 광대역정도를 나타내는데 일반적으로 사용되며, 1 에 가까울수록 광대역 응답을 의미한다. 또한, $D(M O D E L S) / D(R F D)$ 이 1 에 가까울수록 $D(R F D)$ 대비 신뢰도가 높음을 의미한다.

다점계류라인의 피로손상을 추정하는데 있어서 WirschingLight모델은 Vanmarke 밴드폭 매개변수가 1에 가까와지는 광 대역으로 갈수록 피로손상값이 과대평가됨을 알 수 있다. 바이 모달 스펙트럼을 기반으로 한 Jiao-Moan모델은 안정적이나 다 소 과대평가되는 반면 Sakai-Okamura모델은 전반적으로 과소 평가되고 있다. Zhao-Baker모델은 일부 응답스펙트럼에 대해 불안정한 피로손상값을 보여 신뢰하기 어려운 모델로 판단되며, Dirlik모델은 전반적으로 안정적이나 전반적으로 다소 과소평가

Table 2 Load cases for fatigue damage prediction

\begin{tabular}{|c|c|c|c|c|c|}
\hline Spectrum & Items & Case 1 & Case 2 & Case 3 & Case 4 \\
\hline \multirow{4}{*}{ First wave spectrum } & Hs (m) & 8.5 & 2.0 & 5.0 & 5.0 \\
\hline & $\mathrm{Tz}(\mathrm{sec})$ & 20.0 & 8.5 & 9.5 & 9.5 \\
\hline & Heading (deg.) & 160.0 & 160.0 & 180.0 & 180.0 \\
\hline & Type of spectrum & ISSC & ISSC & ISSC & ISSC \\
\hline \multirow{4}{*}{ Second wave spectrum } & Hs (m) & 3.0 & $\mathrm{n} / \mathrm{a}$ & 3.0 & $\mathrm{n} / \mathrm{a}$ \\
\hline & $\mathrm{Tz}(\mathrm{sec})$ & 20.0 & $\mathrm{n} / \mathrm{a}$ & 18.0 & $\mathrm{n} / \mathrm{a}$ \\
\hline & Heading (deg.) & 240.0 & $\mathrm{n} / \mathrm{a}$ & 120.0 & $\mathrm{n} / \mathrm{a}$ \\
\hline & Type of spectrum & JONSWAP & $\mathrm{n} / \mathrm{a}$ & JONSWAP & $\mathrm{n} / \mathrm{a}$ \\
\hline \multirow{3}{*}{ Wind spectrum } & Speed (m/sec) & 3.0 & $\mathrm{n} / \mathrm{a}$ & 1.0 & $\mathrm{n} / \mathrm{a}$ \\
\hline & Heading (deg.) & 270.0 & $\mathrm{n} / \mathrm{a}$ & 90.0 & $\mathrm{n} / \mathrm{a}$ \\
\hline & Type of spectrum & API & $\mathrm{n} / \mathrm{a}$ & API & $\mathrm{n} / \mathrm{a}$ \\
\hline
\end{tabular}




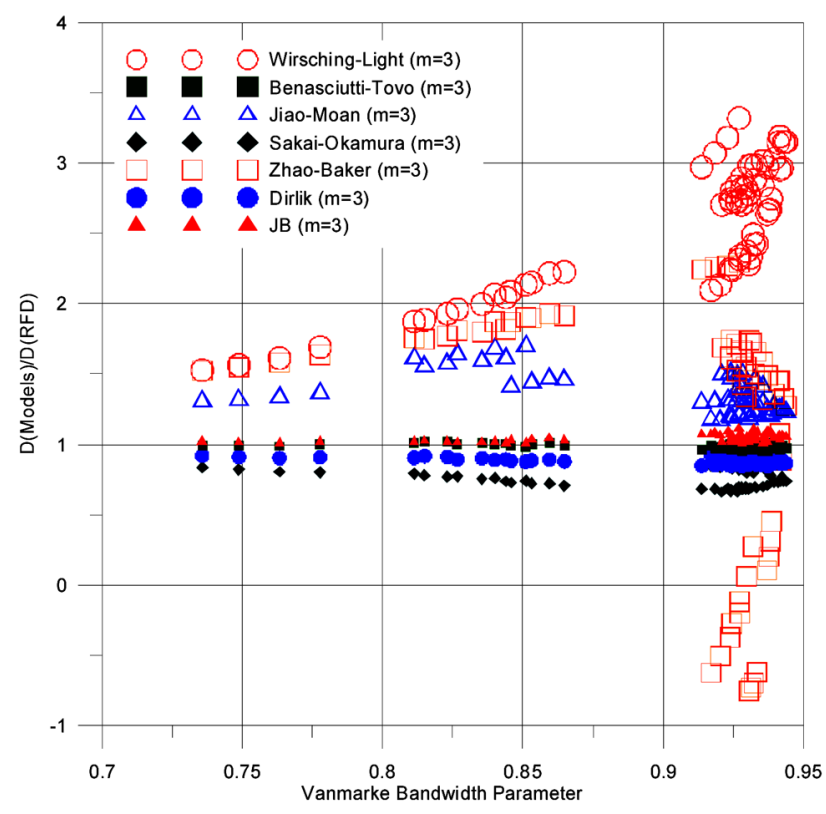

(a)

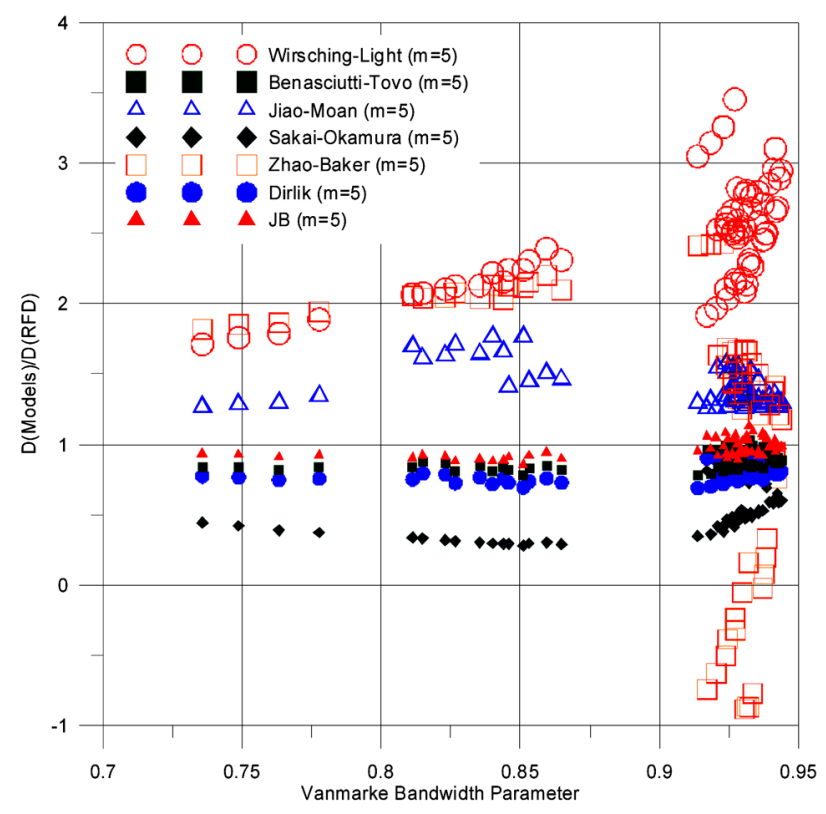

(b)

Fig. 4 Comparision of mooring line damage calculation result by fatigue damage models for (a) $m=3$ and (b) $m=5$.

되는 경향을 보인다. 한편, Benasciutti-Tovo 모델과 JB모델이 전 반적으로 광대역 하중에서도 안정적이며 시간영역피로평가법의 결과와 매우 유사한 피로손상값을 주는 것을 알 수 있다.

해양 플랜트를 설계하는 경우에 매우 높은 안전율을 요구하기 때문에, 과대평가를 하는 피로손상모델을 사용하여 설계를 하는 것이 현실적인 방법일 수 있다. 하지만 실제 문제의 경우, 수많은 복합적인 환경하중에 대해서 과대평가를 하는 피로손상모델을 사용하여 막연히 충분한 안전율이 고려되었을 것이라 판단하고 설 계하기 보다는 합리적으로 평가하는 피로손상모델을 사용하여 얻 은 피로손상값을 얻은 후에 정량적인 안전율을 고려하여 설계 하는 것이 더 바람직한 접근방법이라 사료된다. 이에 본 연구결 과에 따라 광대역 특성을 갖는 계류라인 피로손상평가에 적합 한 피로손상모델로 Benasciutti-Tovo 모델과 JB모델을 제안한다.

\section{4. 결 론}

본 연구에서는 광대역 응답스펙트럼에 의한 피로손상해석에 적 용되는 다양한 피로손상모델들을 소개하고, 부유식 해양플랜트의 계류라인의 피로해석에 적합한 피로손상모델 선정을 위한 수치 해석적 비교연구를 수행하였다. 수치해석 모델로는 서아프리카 해역에서 설치 및 운용되고 있는 $\mathrm{FPSO}$ 의 수동형 다점계류시스 템을 선정하였으며, 이 때, 신뢰성있는 피로손상모델 비교연구 수 행을 위해 가능한 한 다양한 하중조건을 고려될 수 있도록 단일 및 복합 환경하중을 생성하여 작용시켰다. 각각의 피로손상모델 을 적용해 구한 피로손상값은 레인플로우 집계방법에 근거해 시 간영역 피로평가방법으로부터 산정한 값과 비교하여 그 적합성 을 평가하였다. 그 결과 광대역 응답스펙트럼에 의한 부유식 해양 플랜트 계류라인의 피로해석에는 Benasciutti-Tovo모델과 JB모 델이 안정적이고 적합한 모델임을 확인할 수 있었다.

\section{References}

ABS, 2006. Spectral-based Fatigue Analysis for Floationg Production, Storage and Offloading (FPSO) Systems. ABS Guidance Note, American Bureau of Shipping, USA

American Petroleum Institute (API), 2005. Recommended Practice 3rd Edition 2SK Design and Analysis of Stationkeeping Systems for Floating Structures. API.

Benasciutti, D., Tovo, R., 2005. Spectral Methods for Lifetime Prediction under Wide-band Stationary Random Processes. International Journal of Fatigue, 27(8), 867-877.

BV, 2008. Ariane7 User Guide. Bureau Veritas, French

Dirlik T., 1985. Application of Computers in Fatigue. PhD Thesis, University of Warwick.

DNV, 2008. Fatigue Assessment of Ship Structures. DNV Classification Notes No.30.7, Det Norske Veritas, Norway.

Jiao, G., Moan, T., 1990. Probabilistic Analysis of Fatigue due to Gaussian Load Processes. Probabilistic Engineering Mechanics, 5(2), 76-83.

KR, 2010. Guidance for the Fatigue Strength Assessment of Ship Structures. Rules for Classification of Steel Ships, Korean Resister of Shipping, Korea.

Lim, Y.C., Kim, K.S., Choung, J.M., 2010. Fatigue Damage Combination for Spread Mooring System under Stationary Random Process with Bimodal Spectrum Characteristics. Journal of the Society of Naval Architects of Korea, 47(6), 813-820.

Lloyd, 2002. Fatigue Design Assessment, Level 3 Guidance on Direct Calculations. Lloyd's Register, UK. 
Madsen H.O., Krenk S., Lind N.C., 1986. Methods of Structural Safety. Prentice-Hall, Englewood Cliffs, New Jersey Matsuishi, M., Endo, T., 1968. Fatigue of Metals Subjected to Varying Stress-fatigue Lives under Random Loading. In: Paper presented to Japan Society of Mechanical Engineers, Fukuoka Japan, 37-40.

Miner M.A., 1945. Cumulative Damage in Fatigue. Journal of Applied Mechanics, 12, 159-164.

Park, J.B., 2011. The Development of a Fatigue Damage Model for the Wide Band Random Loading. PhD Thesis, Inha University.

Park, J.B., Kim, K.S., Choung, J.M., Kim, J.W., Yoo, C.H., Ha, Y.S., 2011. Data Acquisition of Time Series from Stationary Ergodic Random Process Spectrums. Journal of Ocean Engineering and Technology, 25(2), 120-126.
Sakai, S., Okamura, H., 1995. On the Distribution of Rainflow Range for Gaussian Random Processes with Bimodal PSD. Japan Society of Mechanical Engineers International Journal Series A: Mechanics and Material Engineering, 38(4), 440-445.

Wirsching, P.H., Light, M.C., 1980. Fatigue under Wide Band Random Stresses. Journal of the Structural Division, ASCE (American Society of Civil Engineers), 106(7), 1593-1607.

Zhao, W., Baker, M.J., 1992. On the Probability Density Function of Rain-flow Stress Range for Stationary Gaussian Processes. International Journal of Fatigue, 14(2), 121-135. 